\title{
A Grounded Theory of Young Tennis Players' Use of Music to Manipulate Emotional State
}

\section{Daniel T. Bishop, Costas I. Karageorghis, and Georgios Loizou Brunel University}

\begin{abstract}
The main objectives of this study were (a) to elucidate young tennis players' use of music to manipulate emotional states, and (b) to present a model grounded in present data to illustrate this phenomenon and to stimulate further research. Anecdotal evidence suggests that music listening is used regularly by elite athletes as a preperformance strategy, but only limited empirical evidence corroborates such use. Young tennis players $(N=14)$ were selected purposively for interview and diary data collection. Results indicated that participants consciously selected music to elicit various emotional states; frequently reported consequences of music listening included improved mood, increased arousal, and visual and auditory imagery. The choice of music tracks and the impact of music listening were mediated by a number of factors, including extramusical associations, inspirational lyrics, music properties, and desired emotional state. Implications for the future investigation of preperformance music are discussed.
\end{abstract}

Key Words: emotion, response, qualitative, preperformance routine

Music listening as a preperformance strategy in sport has received limited attention in sport psychology research (e.g., Gluch, 1993) despite evidence for the capacity of music to elicit strong emotions (Gabrielsson, 2001) and for the prevalence of music listening as a mood-regulation strategy in adolescents (Saarikallio \& Erkkilä, 2007). This is possibly due to the idiosyncratic nature of musical preferences and responses to music, which limit the generalizability of findings. However, the idiosyncratic nature of emotional responses to music provides a potential avenue for manipulating athletes' precompetitive emotions.

Regular changeover periods offer tennis players $90 \mathrm{~s}$ of introspection, which may lead to sharp degradation in performance when under pressure (choking; Baumeister, 1984). However, changeovers also afford players an opportunity to positively influence their emotional state, and listening to music can achieve this end (Scherer, 2004; R.E. Thayer, Newman, \& McClain, 1994). Although listening to music is not permitted during play in some major events such as the Wimbledon Championships (Lawn Tennis Association [LTA], personal communication,

The authors are with the School of Sport and Education, Brunel University, Uxbridge, England, U.K. 
October 10, 2005), the International Tennis Federation Junior Circuit Regulations 2007 make no such stipulations at the time of this writing.

Evidence suggests that listening to music during physical activity can reduce perceived exertion (Copeland \& Franks, 1991) and enhance affective state (Boutcher \& Trenske, 1990), and these effects may be mediated by an attentional shift from internal (somatic) cues to external (music) cues (Szabo, Small, \& Leigh, 1999). Musical accompaniment can also improve performance in predominantly aerobic (Atkinson, Wilson, \& Eubank, 2004) and anaerobic (Simpson \& Karageorghis, 2006) events. Karageorghis, Drew, and Terry (1996) examined the effect of stimulative music (tempo, 134 beats per minute $[\mathrm{bpm}]$ ) relative to sedative music $(90 \mathrm{bpm})$ and white noise, when played immediately before execution of a grip strength task. They found that grip strength was greater after listening to the stimulative music; the extent of this effect may be moderated by aspects of the athlete's personality (Crust \& Clough, 2006). Psychophysiological indices of performance also exhibit some relationship with music properties: Heart rate during treadmill walking displays a moderate correlation with preferred music tempo (Karageorghis, Jones, \& Low, 2006); and fast tempo music reduces the latency of neural responses to visual stimuli when contrasted with the same music played at a slower tempo-reflecting a faster evaluation of the stimulus (Amezcua, Guevara, \& Ramos-Loyo, 2005).

To address the problematic issue of selecting appropriate music for sport and exercise contexts, Karageorghis, Terry, and Lane (1999) developed the Brunel Music Rating Inventory (BMRI), which stemmed from a conceptual framework wherein four factors are deemed to contribute to what Karageorghis et al. termed the motivational qualities of music: rhythm response, musicality (both music factors), cultural impact, and association (both personal factors). The BMRI was later redesigned to form the BMRI-2 (Karageorghis, Priest, Terry, Chatzisarantis, \& Lane, 2006), an instrument tailored to exercise environments. However, owing to the complex nature of precompetitive emotions (Hanin, 2000), assessing the motivational qualities of a musical track may not capture the efficacy of music listening as a preperformance strategy. Also, the study of music in sport has focused primarily on the potential role of music as an ergogenic aid when used to accompany performance (e.g., Atkinson et al., 2004), despite the ability of music to elicit enduring autonomic and endocrine responses (Scherer, 2004).

Emotions are an integral part of human existence, mediating almost every facet of our behavior. They comprise physiological (Ekman, Levenson, \& Friesen, 1983), facial expression (Russell \& Bullock, 1985), behavioral (Frijda, 1986), and affective (Russell, 1980) components. Damasio (2000) highlighted the regulatory role of emotions, stating that they lead ". . . in one way or another to the creation of circumstances advantageous to the organism . . . their role is to assist the organism in maintaining life" (p. 51). Although contemporary sport is not a matter of life and death, it has evolved to become a substitute for such situations. Optimal emotional patterns are necessary for sporting success (Hanin, 2000), and there is evidence that music can elicit potentially performance-facilitating neurophysiological (Menon \& Levitin, 2005) and affective (Gabrielsson, 2001) states.

Scherer and Zentner (2001) identified three central routes by which emotions are elicited via music listening. The first of these is the memory route, wherein music acts as a powerful trigger to recollection of an emotive event. The empathy route necessitates the listener's ability to identify the emotions being expressed 
by the performer, which Scherer and Zentner speculated to be most viable when listening to a highly admired performer, or when the music is played in an emotional manner. The final route is appraisal, wherein the perceiver evaluates the personal significance of an event for his or her well-being, according to a number of criteria such as intrinsic pleasantness. Appraisal of pleasantness is a core feature of emotional responses (Russell, 1980) and determines our orientation toward or away from environmental stimuli, including music (Zentner \& Kagan, 1996). Scherer and Zentner also noted two peripheral routes to musically induced emotion: (a) proprioceptive feedback, which they describe as coupling of internal rhythms to external drivers (cf. rhythm response; Karageorghis et al., 1999) and (b) facilitating the expression of preexisting emotions, which refers to the loosening of emotional control typically exhibited in social contexts (Ekman, 1972).

Scherer (2004) noted that music can elicit both utilitarian and aesthetic emotions, defining the former as "high-intensity emergency reactions, often involving a synchronization of many organismic subsystems ... driven by the appraisals in the central nervous system" (p. 241). Utilitarian emotions parallel primary emotions, which may arise through the triggering of innate dispositional representations-patterns of neural activity primed to respond to key stimulus features (Damasio, 1994). Primary emotions have important functionality in allowing us to adapt to highly consequential life events; the feeling of fear is a manifestation of the fight-flight response to a looming predator, for example. The apparently survival-oriented functionality of utilitarian emotions contrasts with that of the rather weaker aesthetic emotions (cf. secondary emotions; Damasio, 1994), which may only elicit symptoms such as goose bumps or moist eyes. According to Scherer, aesthetic emotions are appraisals of visual or auditory stimuli in terms of their artistic qualities, which is somewhat removed from the transactional self-referenced appraisal involved in utilitarian emotions (cf. Lazarus, 1991).

Sloboda and Juslin (2001) delineated two broad sources of emotional responses to music. Intrinsic sources are structural characteristics of the music stimulus (e.g., tempo), which primarily mediate emotional intensity to promote action tendencies (Frijda, 1986) via well-established subcortical mechanisms (see Panksepp, 1998). Extrinsic sources are psychological in nature and may be iconic (i.e., derived from resemblance between the overall musical structure and some other emotive agent) or associative-arbitrarily formed through associative learning, oftentimes via single-trial conditioning. Sloboda and Juslin proposed that extrinsic sources are stronger determinants of the content of musically induced emotions (e.g., positive or negative).

The circumplex model of affect (Russell, 1980) offers a template for assessing both the content and intensity of emotions experienced in sport. The circumplex comprises two bipolar perpendicular dimensions - activation (arousal) and valence (pleasantness) — which bisect to subdivide the circumplex, yielding four quadrants. Proponents of the circumplex contend that every experienced emotion can be located at some point within one of the four quadrants. For example, excitement lies in the extremities of the quadrant bordered by the upper halves of the activation and valence continua (highly arousing-highly pleasant). Russell, Weiss, and Mendelsohn (1989) subsequently developed the Affect Grid, which they concluded to be a reliable and valid measure of both arousal and pleasure. This single-item measure has since been successfully employed as a measure of in-task affect during simulated driving performance (Edmonds, Mann, Tenenbaum, \& Janelle, 2006). 
North and Hargreaves (1997) used a two-item measure to investigate musically induced emotions and concluded that ratings of the emotions expressed by a musical excerpt can be reliably predicted by (a) the extent to which listeners like the piece and (b) the extent to which they are aroused by it, an assertion which has since received empirical support (Ritossa \& Rickard, 2004). Arousal is a concept central to many theories and models of emotion (e.g., J.F. Thayer \& Faith, 2001), and arousal regulation strategies have been posited as important moderators of emotional control in sport (Jones, 2003). Liking for musical stimuli is related to the pleasure derived (Ritossa \& Rickard, 2004), and happiness - a key component of the feeling of pleasure-has attracted attention in sport emotion research (Jones, Lane, Bray, Uphill, \& Catlin, 2005). Therefore, circumplex-based measures such as the Affect Grid (Russell et al., 1989) present informative yet expedient tools for measuring emotional responses to music listening in sport.

\section{Summary}

To date, considerable research has been conducted on the ideal emotional state for performance (e.g., Edmonds et al., 2006), emotional responses to music (e.g., Scherer, 2004), and the psychophysical effects of music in sport and exercise (e.g., Karageorghis et al., 1996). However, music listening as a preperformance strategy to elicit facilitative emotions in sport remains largely underresearched. Although habitual music use by athletes has been reported (Gluch, 1993), there is still little understanding of the processes by which preperformance music is selected, or of its intended or actual affective consequences.

Therefore, the main objective of this study was to examine the use of music to manipulate emotional states by young tennis players who indicated the use of music listening as a preperformance strategy, to gain a better understanding of their emotional responses to music and the factors that mediate these responses. Research on musically induced emotions (e.g., Scherer, 2004) and music listening in sport and exercise (e.g., Karageorghis et al., 1999) was used in conjunction with pilot data to develop a suitable interview schedule (Patton, 2002). Participants recorded their emotional responses to music heard during interview using a variant of Russell et al.'s (1989) Affect Grid and discussed their reasons for selection. Some participants agreed to complete a 2-week diary detailing their daily music listening, together with their reasons for listening, and emotional responses to music. All emergent concepts were incorporated into a model that will provide a template to guide (a) athletes' music selections and (b) future research efforts that seek to identify causal relationships between emotional responses to preperformance music and performance itself.

\section{Method}

\section{Pilot Interviews}

Following institutional ethics approval, seven unstructured pilot interviews were conducted with a convenience sample of two women and five men (mean age = 26.1 years, $S D=4.7$ years), in order to develop a suitable interview schedule, and to inform the first author's interviewing style for the main study. Interviewees participated in a range of sports (rowing, basketball, marathon running, hockey, 
weightlifting, tennis, and soccer), and represented a range of competencies (recreational to international). Participants were asked generic questions relating to their music use, such as "What do you listen to as part of your preperformance preparation?", "How do you decide to listen to that choice of music?", and "How does it make you feel?"

The pilot study revealed a potential methodological problem: the difficulty inherent in eliciting information from participants about why they would select any given music track. Very little, if any, conscious thought was given to the underlying reasons for selection of a given track or artist; the reason was largely reduced to a simple "because I like it." This necessitated the development of suitable elaboration probes (Patton, 2002), such as "What do you like about it?" Pilot study participants also found difficulty in remembering and naming tracks; therefore, participants selected to take part in the main study were asked to complete a preinterview questionnaire and were requested to bring five of their preperformance music tracks to interview.

\section{Participants}

An international junior tennis center in southwest London, England, catering to young tennis players from a wide variety of sociocultural backgrounds, was chosen as a suitable site for data collection. It was anticipated that this site would expedite the selection process, facilitate cross-case comparisons, and allow subsequent refinement and extension of ideas emanating from the data (Dey, 2003).

An initial questionnaire was administered to 67 players at the center; LTA rating was used as an index of respondents' current ability. Forty-seven players returned the questionnaire and the data collated were used to purposively select players for interview according to a number of informativeness-related criteria: (a) those participants who had provided questionnaire responses that described their music listening habits in the greatest detail; (b) those with an LTA rating of 5.1 and above, as they occupy the top $10 \%$ of all British players; (c) and those who had indicated music listening as part of their performance preparation routine.

Fourteen participants, seven women and seven men (mean age $=18.4$ years, $S D=1.97$ years) who satisfied the inclusion criteria and had at least 5 years' competitive tennis experience ( mean $=7.4$ years, $S D=2.6$ years), were recruited. The ethnicities represented comprised White UK/Irish $(n=10)$, White European $(n=$ 2), Afro Caribbean $(n=1)$, and White US $(n=1)$.

\section{Interview Guide}

Respondents' answers to the initial questionnaire and a literature search highlighted a number of sensitizing concepts on which to build a loose interview guide (example questions in parentheses): music properties ("Are there any particular segments of this track you like?"); extramusical associations ("Does it make you think of anything?"); sociocultural variables ("How do you think this music is perceived by your peers?"); music-related imagery ("Does this music conjure up any images?"), and listening habits ("Where are your top three places for listening to music?"). It also became apparent during the first interview that the guide should be shorter and less specific; therefore, it was amended accordingly (the final version is available on request from the principal author). 


\section{Interview Materials}

Interviews were recorded using a digital voice recorder (Olympus VN-480PC; Olympus Corporation, Tokyo) and were transferred onto a laptop computer via a software interface (Olympus Digital Wave Player v. 2.0.0; Olympus Corporation, Tokyo) for ease of transcription. In vivo notes were taken, to capture nonverbal information and any key concepts that emerged. The note-taking process also assisted the first author in pacing the interview appropriately (Patton, 2002).

\section{Procedure}

Preinterview Music Questionnaire. Players selected at the preliminary stage were invited to take part in a 1-hr interview about their music listening habits, and their use of music in the context of tennis. Each participant was given a paper catalog containing 2,024 music tracks from the first author's personal music collection. These tracks were grouped by genre (e.g., alternative, R 'n' B, classical) and then alphabetized; all catalog entries were held in electronic music format. To ensure that performance-related music was discussed at interview, the front sheet of the catalog requested that participants list five emotional states they deemed crucial for success in tennis, and to specify music tracks that made them either feel or think about each state. Participants were asked to bring along any music tracks not included in the catalog to the interview. All selected tracks were played during the interview to stimulate discussion.

Interviews. Participants read an information sheet and provided written informed consent. Interviews took place in a quiet room, lasted 37 to $84.5 \mathrm{~min}(M=52.4$ $\mathrm{min}$ ), and were digitally recorded. Music tracks were played from audio software via a stereo receiver (Pioneer SX-205RDS; Pioneer Corporation, Tokyo), which outputted through two 50-W speakers (Pioneer CS-767; Pioneer Corporation, Tokyo) placed $2.2 \mathrm{~m}$ apart and equidistant $(1.2 \mathrm{~m})$ from the participant. Mounted on a tripod at the level of the participant's head height, a digital meter measured the sound intensity (model AZ 8928, AZ Instrument Corporation, Taichung City, Taiwan; this meter was calibrated using a Brüel and Kjær [Nærum, Denmark] Sound Level Calibrator, type 4231). Before discussing each selected track, the researcher requested that participants adjust the intensity of the music to one that they would typically apply to engender the named emotional states. They were also requested to rate each track not only for liking and arousal potential (cf. North \& Hargreaves, 1997), but also for familiarity and popularity with peers, on 11-point bipolar scales; this was done while listening at a standardized intensity of $55 \mathrm{dBA}$. It was expected that the combination of qualitative and quantitative data would give a "powerful mix" (Miles \& Huberman, 1994, p. 42).

Diary. Ten of the 14 participants agreed to complete a 2-week, page-a-day diary. Participants were informed that seven completed pages would be sufficient, but anything more would be helpful, and that they would receive three text messages on their mobile phone per day: in the morning, at lunchtime, and in the evening. The morning and lunchtime messages served as prompts for the participant to recall and note any music heard up until that point; it was expected that this preconscious prompting would facilitate subsequent recall of a behavior that tends to proceed in 
a relatively habitual — and therefore unmemorable—fashion. The evening message served as a prompt to complete that day's page.

Each page required the completion of a brief summary of daily activities carried out while listening to music, and details of a memorable music listening episode on each daily page. It was decided that, although very few music listening episodes would relate directly to music listening immediately before performance, to have such a narrow focus would provide too few data. Given that music may be an effective moderator of preperformance mood (Gluch, 1993), that athletes exhibit symptoms of competition-related emotions up to 1 week before competing (Hanton, Thomas, \& Maynard, 2004), and that all participants were engaged in at least one competitive event during the diary completion period, all music listening episodes were considered relatable to the aims of the study. Participants were asked to $\log$ as many episodes as they could recall, and rated any music heard during diary completion for both liking and arousal potential.

Observations. Rapley (2003) asserted that "No form of interview study, however devious or informal, can stand as an adequate substitute for observation data" (p. 29); nonetheless, observable phenomena of music listening are scarce. During playback of each track, the first author recorded changes in participants' facial expressions and behavior (e.g., smiling, piloerection, and increased liveliness); in vivo notes on the interview schedule indicated the precise nature and timing of these changes.

\section{Data Analysis}

Grounded theory (Glaser \& Strauss, 1967) was chosen as the appropriate method for data collection and analysis because it is a technique for developing theory from actual data. In accordance with the tenets of grounded theory, interviews were semistructured so as to allow for the emergence of novel information offering new directions. Even though emergent theory was grounded in the raw data, there was inevitable interplay between the first author and the data, which could have led to the identification of themes concordant with the researcher's beliefs, to the exclusion of others. Therefore, a number of precautions were taken to minimize the impact of such biases, most important of which was triangulation (Miles \& Huberman, 1994).

Triangulation was achieved by utilizing diverse data sources (e.g., gender, age, ethnicity, and musical preferences); multiple data types (e.g., written notes, interview transcripts, diary notes); an array of methods (interview, diary, observation); and recruitment of other researchers, who did not participate in data collection, to assist in data analysis. All raw interview and diary data were given to a peer debriefer who possessed knowledge of both psychomusicology and music listening in sport, to either corroborate or refute the first author's interpretations of the raw data, and to suggest alternative explanations. Interrater agreement for interview data was $93 \%$, and interrater agreement for diary data was $95 \%$; this procedure could not be performed for observation data. Other procedures were conducted with regard to trustworthiness criteria in qualitative research (Lincoln 
\& Guba, 1985): The first author was engaged with the data for a prolonged period, persistently observed the participants, identified negative instances, kept a reflexive journal, and gave copies of interview transcripts to participants in order to confirm their representativeness.

Coding Procedures. Interview data were analyzed immediately and compared with existing data (constant comparison, Glaser \& Strauss, 1967), in order to establish whether or not there was anything worth pursuing (C.F. Seale, personal communication, January 11, 2005): Recurrent themes (e.g., the presence of memorable life episodes in relation to selected music) emerged after a visual inspection of the first three interview transcripts; this prompted the continuance of data collection, regardless of diary data contribution (the first completed diary was only returned 2.5 weeks after interview).

Preinterview Music Questionnaire Data. Participants listed a total of 70 emotional states that they deemed crucial to their success in a tennis match. Identical responses across participants enabled immediate reduction into 42 raw data themes (Table 1), which the first and third authors independently clustered into 16 and 19 first-order themes, respectively. On discussion, it was mutually decided that 18 first-order themes best represented the raw data obtained (interrater agreement $=$ $100 \%)$. The first and third authors independently grouped these themes into five and seven dimensions, and subsequently agreed that five general dimensions ultimately provided the most parsimonious representation of the data.

Interview and Diary Data. All interview and diary data were fully coded and analyzed inductively using QSR NVivo (v. 2.0): Complete Word file transcriptions were imported into NVivo, where free nodes (cf. open coding, Strauss \& Corbin, 1998) were used to categorize chunks of text. Free nodes were created $(N=$ 1,087), which were then grouped into 57 trees (cf. axial coding, Strauss \& Corbin, 1998). All tree concepts were subjected to a visual inspection, and were combined where appropriate in order to develop central categories. The decision to include a concept as a central category was made according to frequency of occurrence: Central categories were chiefly included owing to either (a) their occurrence across all participants and all data sources or (b) their frequent occurrence across data sources only. When the development of categories reached theoretical saturation (Strauss \& Corbin, 1998) data collection ceased. In accordance with Strauss and Corbin's (1998) guidelines for selective coding, all central categories were incorporated into the model in Figure 1, so that the findings could be presented as a set of interrelated concepts.

\section{Results}

The initial questionnaire, preinterview music questionnaire, interview, and diary collectively yielded qualitative and quantitative data pertaining to the how, what, when, where, and why of participants' music listening. Figure 1 depicts an integration of all emergent concepts into a process model; these concepts are elucidated below. 


\section{Table 1 Intended Emotional Outcomes of Music Listening}

\begin{tabular}{|c|c|c|}
\hline Raw Data Themes $(k=42)$ & First Order Themes $(k=18)$ & General Dimensions $(k=5)$ \\
\hline \multicolumn{3}{|l|}{ Able to focus } \\
\hline Accept bad shots and move on & Ability to focus & \\
\hline \multicolumn{3}{|l|}{ Concentration } \\
\hline \multicolumn{3}{|l|}{ Clear mind } \\
\hline \multicolumn{3}{|l|}{ Clear mind under pressure } \\
\hline \multicolumn{3}{|l|}{ Clearly focused } \\
\hline \multirow{2}{*}{\multicolumn{3}{|c|}{$\begin{array}{l}\text { Focused } \\
\text { Zoned in }\end{array}$}} \\
\hline & & \\
\hline \multicolumn{3}{|l|}{ Keyed in } \\
\hline \multicolumn{3}{|l|}{ Mentally in control } \\
\hline Mentally prepared & Mentally prepared & \\
\hline Prepared & & \\
\hline Belief and confidence & Self-belief & \\
\hline \multicolumn{3}{|l|}{ Confident } \\
\hline Fearless, courageous & Confidence & Confident \\
\hline Remembrance of previous good play & Past performance success & \\
\hline Feeling fresh & Feeling fresh & \\
\hline General happiness & Feeling happy & \\
\hline \multicolumn{3}{|l|}{ Positive } \\
\hline Positive attitude & Positivity & Posituve emotional state \\
\hline \multicolumn{3}{|l|}{ Positive/happy } \\
\hline Tough (mentally) & Mentally tough & \\
\hline \multicolumn{3}{|l|}{ Energized } \\
\hline Excited/eager & Energized & \\
\hline \multicolumn{3}{|l|}{ Fire it up } \\
\hline \multicolumn{3}{|l|}{ Motivated } \\
\hline \multicolumn{3}{|l|}{ Wanting the satisfaction of winning } \\
\hline \multicolumn{3}{|l|}{ Determined } \\
\hline \multirow{2}{*}{\multicolumn{3}{|c|}{$\begin{array}{l}\text { Motivated (ready for anything) } \\
\text { Never give up }\end{array}$}} \\
\hline & & \\
\hline \multicolumn{3}{|l|}{ Prepared for a fight } \\
\hline \multicolumn{3}{|l|}{ Willing to fight to end } \\
\hline \multicolumn{3}{|l|}{ Up for it } \\
\hline Psyched-up & Psyched up & \\
\hline \multicolumn{3}{|l|}{ Pumped-up } \\
\hline Pumped & Pumped up & \\
\hline \multicolumn{3}{|l|}{ Calm } \\
\hline Calm thinking & Calm & \\
\hline \multicolumn{3}{|l|}{ Calmness } \\
\hline Loose/"no worries" & No worries & Relaxed \\
\hline Relaxed & Relaxed & \\
\hline Relaxed/chilled/breathe & Relaxed & \\
\hline
\end{tabular}




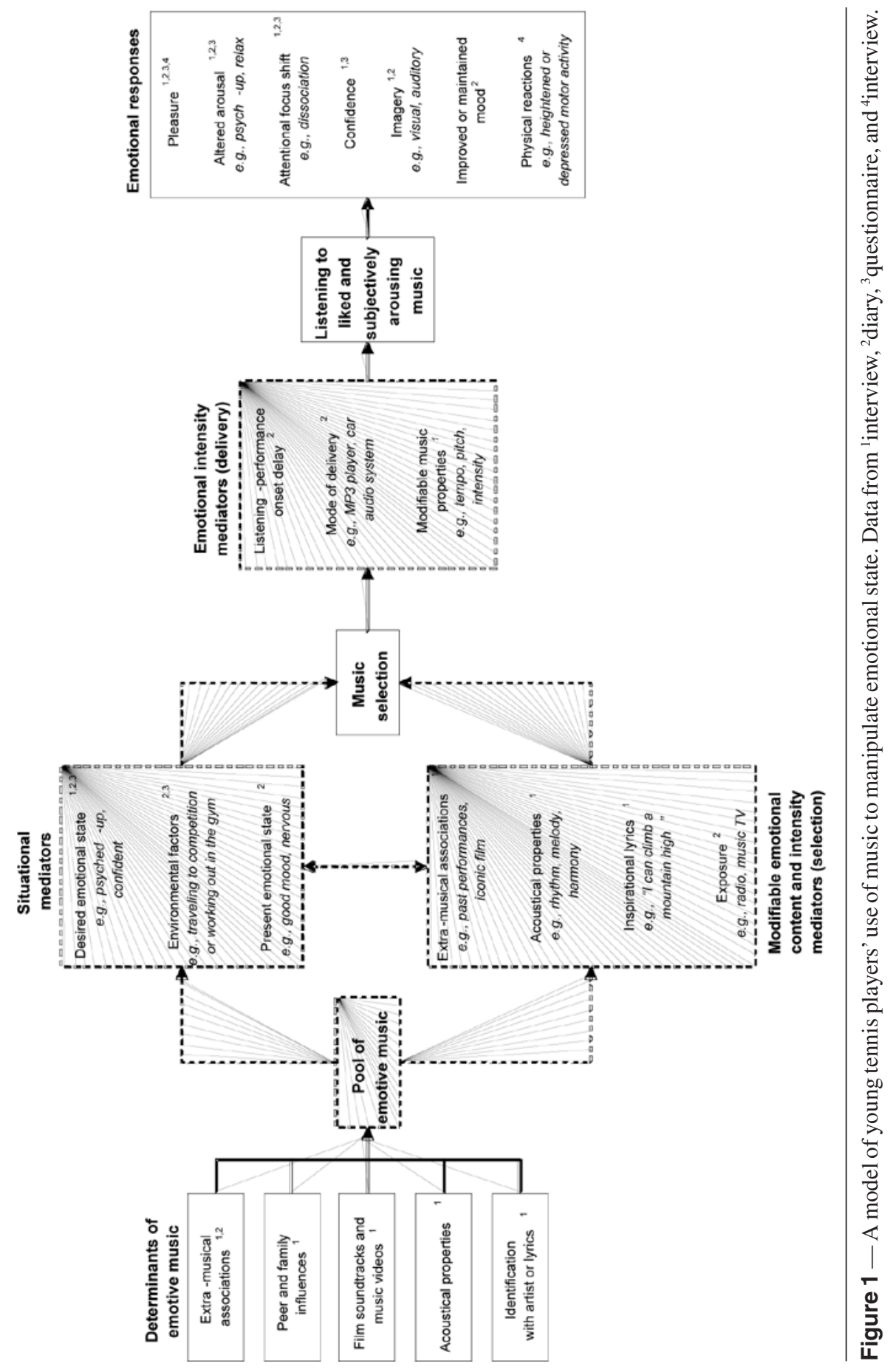




\section{General Overview of Participants' Listening Habits}

Initial questionnaire data indicated that participants enjoy listening to indie, light rock, rap, R 'n' B, garage, rock, easy listening, dance, old skool, love songs, hiphop, techno, and alternative (a full listing of genres is available on request from the principal author). The overlap between many of these categories (e.g., old skool and hip-hop) may reflect the growing implicit perception of music as a homogenous entity. Data also indicated that participants used music to psych up; to feel more positive, motivated, and confident; and to dissociate from external stressors.

Interview and diary data indicated that participants listened to music daily, for $2 \mathrm{hr}$ or more, on average. Data from the initial questionnaire, interviews, and diary pages indicated that participants were predominantly traveling, preparing for tennis (including in the locker room), in their bedrooms, or working out in the gym when listening to music. All participants listened to commercial radio stations and watched music video channels (e.g., MTV) daily when at home.

\section{Music Selection}

Central to the present data, and the model in Figure 1, is that participants purposely selected music to attain a desired emotional state. This was borne out in the initial questionnaire, and participants' responses to the preinterview music questionnaire indicated that they deliberately selected music to elicit five broad categories of emotional states: appropriate mental focus, confident, positive emotional state, psyched up, and relaxed (see Table 1). This too was corroborated by interview data:

I listen to this a lot before I go to matches and before matches, together with the last track, being the last song I've heard, when I get out of the car, to give me that feel-good factor. (Participant 14)

Sometimes, when . . I'm playing bad, I might bring out my iPod, like at a changeover, and maybe listen to this song, to give me a confidence boost. . . . Or if I'm [annoyed], I'll listen to a relaxing song that will make me chill out. It helps a lot. (Participant 9)

This use of music had been developed by some participants to such an extent that they used a medley of tracks in an attempt to optimize their emotional state:

The thing is [tracks] 1, 2, 4, and 5 are needed to feel [confident]. So I was trying to find a song that makes me feel [confident], but there isn't one song that does that. But listening to all of these four songs makes me feel these four things, which makes me feel confident. I haven't found a [single] song yet which makes me feel confident. (Participant 4)

The five categories of reported emotional outcomes of music listening were integrated into the final stage of the model in Figure 1.

\section{Determinants of Emotive Music}

Interview data indicated that five factors repeatedly occurred across and within participants, to determine the likeability and arousal potential of participants' pool of emotive music: extramusical associations, peer and family influences, the 
involvement of the music in film soundtracks and music videos, acoustical properties, and identification with artist or lyrics.

Extramusical Associations. Extramusical associations with significant persons, places, or past events were a prominent feature in many (49/70) of the tracks selected by participants. These associations were often formed as a result of single-trial conditioning:

Can you hear it? The football? He says the bit, “. . . they've taken the lead in the European Championship final," and whatever. It just reminds me of Euro 2004 [soccer championships], Greece winning it . . it like, brings back happy memories, helps me forget about everything else. (Participant 10)

There was also evidence of participants specifically associating tracks with good past performance:

I'm choosing Another Day because that reminds me of this girl called [Lauren]. . . . I wanted to use a word that means something to me; I couldn't use fight. . . . I wanted something that's going to be mental arousal on different levels. ... So that's why I use John Secada, because it reminds me . . . of good tennis. (Participant 8).

If I listen to this song before a match, and I play really well . . . if I hear it again, then I'll think of stuff in the match, how well I did, if I'm just like in my room. (Participant 11)

Participants could also provide specific details of associated significant places, events, or others associated with the memorable music tracks that they described on diary pages (Table 3).

Peer and Family Influences. Some participants indicated that their peers or family members introduced them to a music track:

I never used to like Matchbox 20, I used to hate music like that; then [a friend] introduced me to one track of theirs, and I thought I'd give it a shot, and now I like listening to it. ... It's weird how things change. (Participant 9)

All tracks were rated as relatively popular with peers, with the exception of those selected to elicit a positive emotional state (see Table 2):

Oh, again, no, they won't like this. Then again, that's something that I pride myself on . . . I don't really care what other people think . . . if it's cheesy, I don't care. (Participant 8)

Film Soundtracks and Music Videos. Film soundtracks were highly prevalent in the musical selections provided by participants. This extended to some now-clichéd tracks from the Rocky film series, four of which were on general release before 12 participants had been born:

I love those movies because my dad said, when I was about 13 , you really should watch Rocky. He put it on one morning, and I just loved it. . . . I'm not a massive fan, but you can watch it any time, it just gets you so pumped up, 


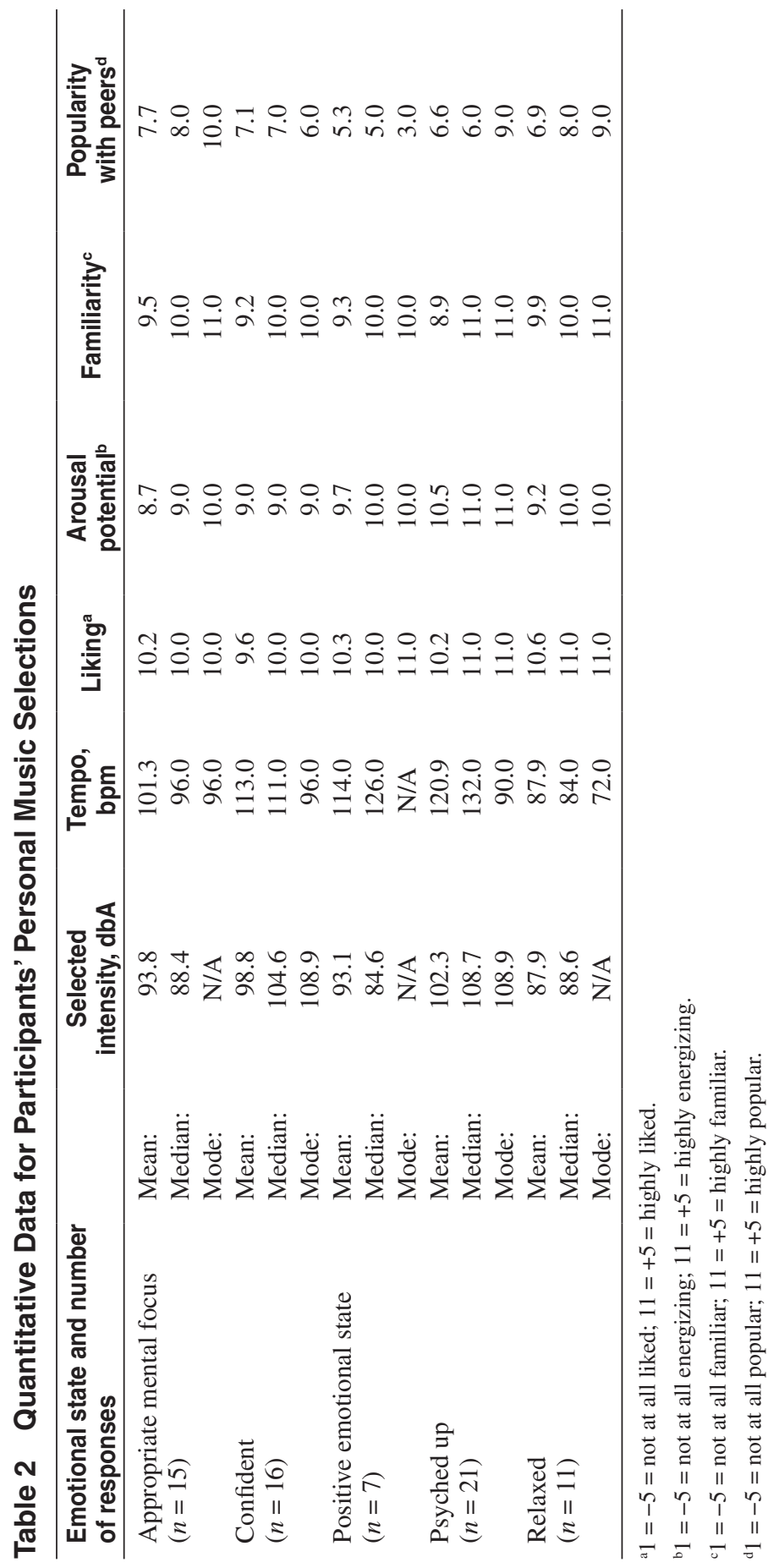


and the song just sticks, and it . . just gets you ... pumped-up for anything. (Participant 4)

[because] it reminds me of . . how I've been preparing . . . I've got to the match and I've prepared myself, and . . . in the Rocky films, this is the music when he was training for his fights; this is the music he was listening to. And when I'm doing my training, I listen to this as well. (Participant 6)

Other participants selected tracks from films without sporting connotations:

I heard it in Johnny 5 . . the Short Circuit film . . . I saw it quite recently, [because] I haven't seen it since I was really little, and we always really liked it. I saw it quite recently ... a the end it's really good. (Participant 3)

All participants watched music video channels, and the videos accompanying music tracks were often easily recalled:

she's in this house, like Alice in Wonderland, and I just think of that every time I hear this song; I don't know why. It's just something that sticks in my mind. (Participant 5)

she's got black wings on. She's just walking around singing it, and he's dragging his guitar. But apart from that, it's just like a deserted caravan park. (Participant 3)

Acoustical Properties. The properties of the tracks were cited as factors influencing participants' selection of music:

it's a really soothing tune. It doesn't, like, work me up, and it doesn't like, go over the top; it's just nice and level. (Participant 11)

It just makes me relaxed. It's not very loud; it's not heavy beats, heavy bass; it's just very like, relaxed. (Participant 9)

And also I like this bit; it's in the middle of the song, and it changes, and she holds the same note for a long time, and again, it like builds up and then it's back to the words again that make me feel that I can accomplish things. (Participant 12)

Identification with Artist or Lyrics. There was evidence that participants listened closely to the lyrics of their selections and empathized with the artists (empathy; Scherer \& Zentner, 2001), and further, that this formed part of the decision-making process when selecting tracks:

This is, again . . . the lyrics of this song, I think, make a lot of girls feel confident. She's basically talking about, "Boyfriend, there you go, and don't come back!" She's really standing up for what she thinks. (Participant 11) 


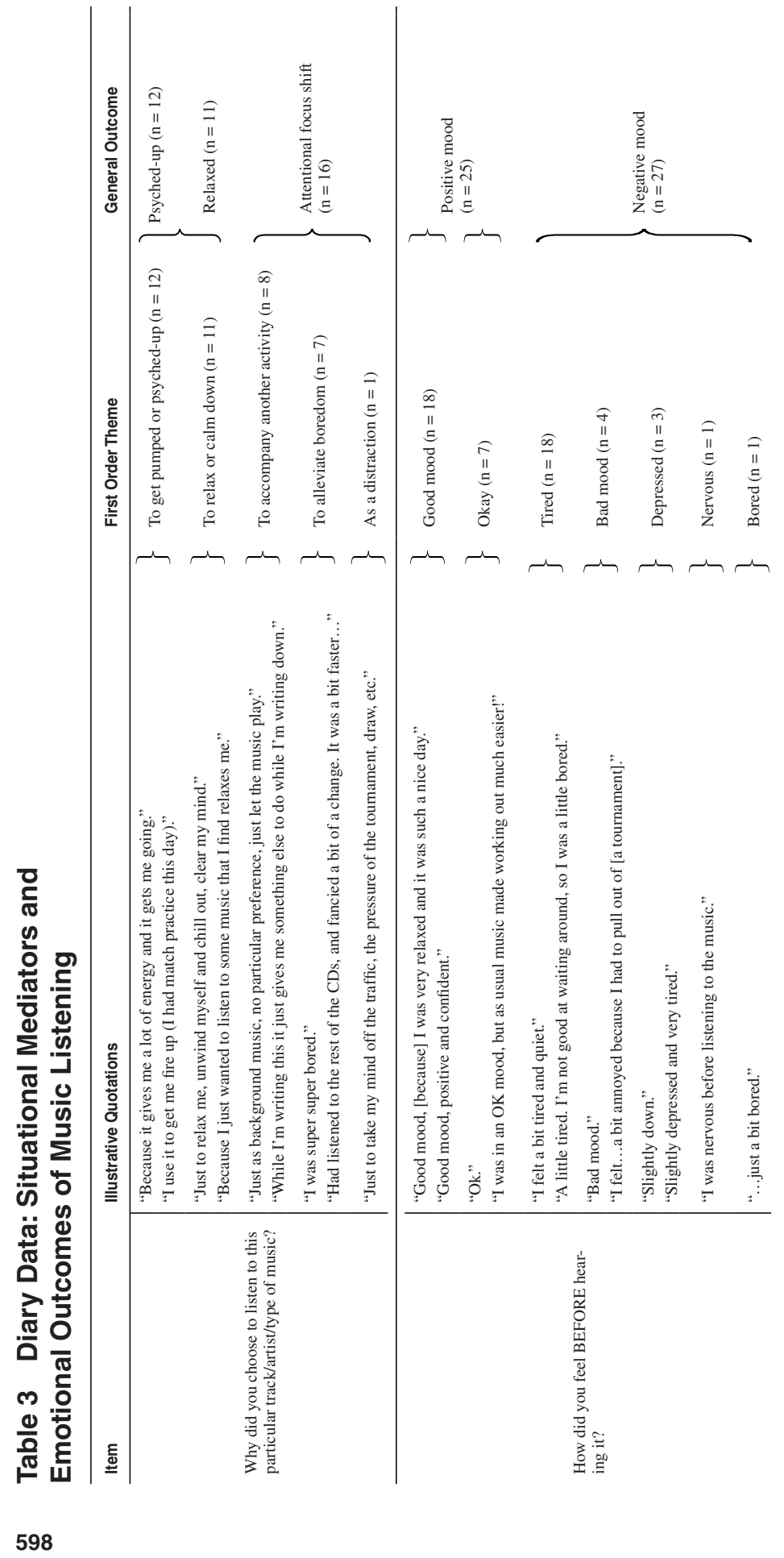




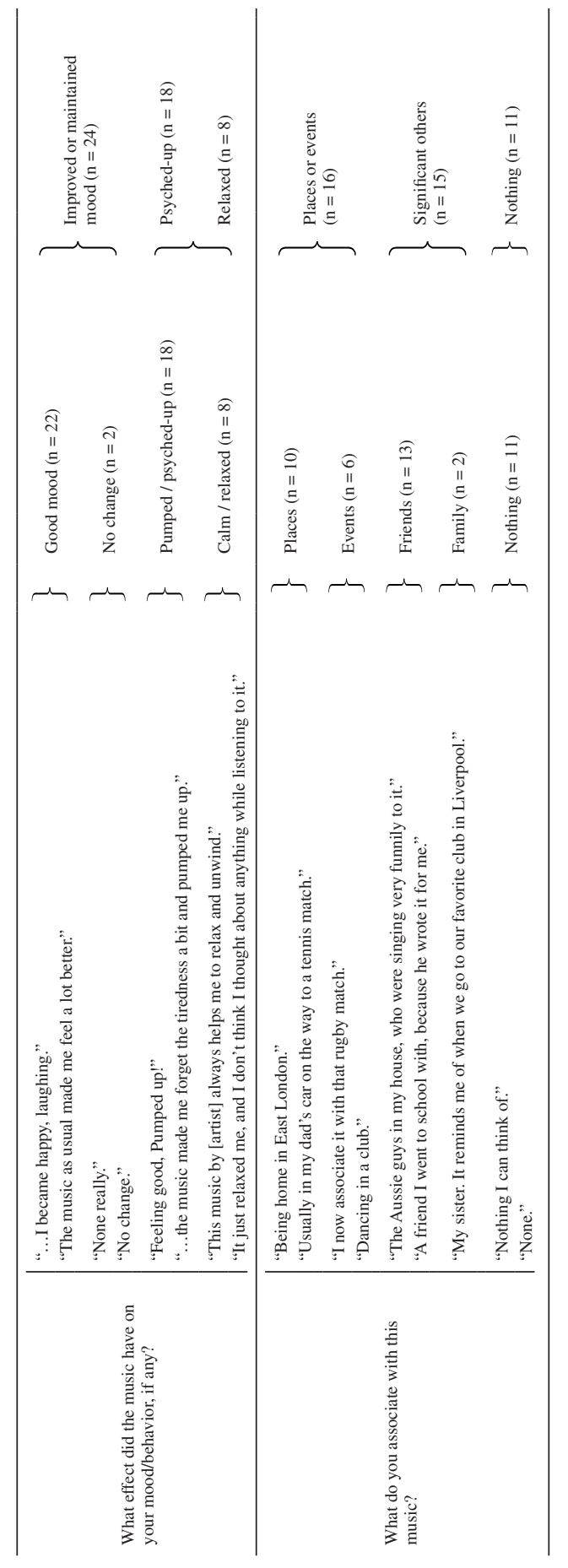


Um, there's like, "I can climb a mountain high." . . . It's just like, I can do anything, I can achieve anything. It makes me think of that when I listen to it. (Participant 12)

\section{Emotional Responses to Music}

All personal music tracks discussed in interview-without exception - were rated as highly liked, highly arousing, and highly familiar (see Table 2); this was irrespective of the intended emotional outcome. Participants' mean ratings for liking and arousal were located in the upper-right quadrant of Russell et al.'s (1989) Affect Grid. Tracks chosen for psyching up were played at the highest intensities and exhibited faster tempi than tracks selected for other emotional outcomes; tracks selected for relaxation were lower in intensity and slower in tempo (see Table 2).

Three broad categories of emotional responses to music listening, intended or reported, emerged as primary themes in diary data (see Table 3). Participants indicated that they used music in order to psych up, relax, and/or to promote an attentional focus shift; feeling more psyched up or relaxed; and improved or maintained mood were frequently reported outcomes. All participants reported imagery in response to music heard during interview and exhibited overt physical reactions.

Imagery. Participants used vivid description of visual images when listening to music during interviews, and sometimes appeared to reminisce:

I can actually picture one of the goals I scored when this is playing. . . I just can't think of anything bringing back such a strong memory as this song ... it's so vivid, especially if I close my eyes, especially when I'm listening to this song. I remember the goal I scored, the pitch we were playing on, I remember everything. (Participant 8)

Participants also described auditory imagery, which can be described as "hearing in the mind's ear" (A.P. Moran, personal communication, September 5, 2005): Participants remarked that they sing along to various tracks, even in the absence of the physical stimulus; this extended to hearing the song in their mind's ear while on court:

Yeah, I sing on court. ... It would be "California," or a specific one. It would be specific phrases in my head. (Participant 2)

Physical Reactions. Given that emotional responses have behavioral (Frijda, 1986) and facial expression (Russell \& Bullock, 1985) components, participants' reactions to music tracks were noted and subsequently incorporated into the model (see Figure 1). The most frequently observed reactions were smiling (in response to 58 out of 70 tracks), increased motor behavior (24/70), and piloerection (7/70); however, these responses did not differ as a function of the intended emotional outcome of listening to each music selection. 


\section{Discussion}

The main objectives of this study were (a) to examine the use of music to manipulate emotional states by young tennis players who indicated the use of music listening as a preperformance strategy, in order to gain a better understanding of their emotional responses to music and the factors that mediate these responses, and (b) to put forward a model grounded in the present data that will provide a template to guide not only athletes' music selections, but also future research efforts that seek to identify causal relationships between emotional responses to preperformance music and performance. Qualitative and quantitative interview and diary data were combined to generate a grounded theory of this phenomenon. Grounded theory (Glaser \& Strauss, 1967) was considered the best method because such an approach is most likely to enhance our understanding and to guide subsequent action (Strauss \& Corbin, 1998).

Central to the present data is the fact that all participants selected music to manipulate their emotional state. Music selections were highly idiosyncratic: Considerable interindividual differences existed in the genre and acoustical properties of tracks selected to achieve identical emotional states. For example, Participant 1 selected Still D.R.E. by Snoop Dogg and Dr. Dre (Gangsta Rap; 92 bpm) in order to feel confident, whereas Participant 3 selected Holding Out for a Hero by Bonnie Tyler (Power Ballad; 144 bpm) to achieve the same end. Some participants used a medley of tracks in an attempt to attain an ideal emotional state, consistent with the notion that idiosyncratic emotional profiles are necessary for successful sporting performance (Edmonds et al., 2006). Given that (a) research has shown that emotional profiles fluctuate considerably in the week leading up to competition (Hanton et al., 2004), (b) music listening pervaded daily diary entries, and (c) improved/maintained mood was an oft-cited consequence of music listening, stricter control of music heard in the lead-up to competition may be an important strategy for regulating young athletes' preperformance mood, a notion supported by work examining nonathletic populations (Saarikallio \& Erkkilä, 2007; R.E. Thayer, Newman, \& McClain, 1994).

The determinants of participants' emotive music in the present model can be delineated according to Sloboda and Juslin's (2001) classification of extrinsic and intrinsic sources of emotion in music. Four of the five determinants can be classified as extrinsic factors; by contrast, acoustical properties are intrinsic. Extrinsic sources of emotion were mentioned more frequently, and with greater description, than intrinsic sources. Participants' music selections were also highly idiosyncratic (typified by a broad range of artists and genres represented), which may reflect the inescapably unique combination of peer and family influences on their cultural exposure to music (North \& Hargreaves, 1995). Thus, extrinsic sources appear to be stronger determinants of emotional content than are the acoustical properties, as per Sloboda and Juslin's (2001) assertion. Music also offers young people the opportunity to create a strong, albeit temporary, unique self-identity (Larson, 1995). Participants were able to draw such an identity from the artist's performance of the selected tracks (empathy route; Scherer \& Zentner, 2001), which might have occurred independently of peer and familial influences. 
Whereas some data were evidently determinants of, or responses to, music listening, other recurrent data concepts were not so clearly delineated. These concepts were combined with extant research (e.g., Scherer \& Zentner, 2001) to develop a set of theoretical mediatory factors for inclusion in the model (demarcated by dashed lines in Figure 1). They were included so that process - an essential part of Strauss and Corbin's (1998) approach to theory building - could be incorporated into the model. Diary data indicated three potential situational mediators of liking and arousal potential. Participants had a desired emotional state to attain, largely to psych up, relax, or dissociate, which suggests that improvement of emotional state was an important regulatory goal (cf. Saarikallio \& Erkkilä, 2007). Their present emotional state was quite often negative, indicating that music more frequently served to enhance mood (R.E. Thayer, Newman, \& McClain, 1994). Further, all data sources uncovered a diverse array of listening environments, including in a car, on a train, in the locker room, on court, and in the gym. Given the interaction between affective auditory and visual stimuli (Baumgartner, Lutz, Schmidt, \& Jäncke, 2006), the impact of music might have been diminished or enhanced by such environmental factors. Thus, practitioners choosing to prescribe music listening as a preperformance strategy should take the athlete's immediate environment into account when doing so.

Three determinants of emotive music were considered modifiable, in that the athletes are able to base their instantaneous selection upon these factors, in order to manipulate the content and intensity of the experienced emotions. The three were extramusical associations, acoustical properties, and inspirational lyrics. Because (a) all participants watched music video channels and listened to commercial radio stations, and (b) evidence exists for a positive relationship between exposure and music preferences (North \& Hargreaves, 1995; Witvliet \& Vrana, 2007), exposure was also included as a potentially influential mediator. This refers not only to the frequency and volume of exposure to music tracks, but also to the pairing of tracks with a strongly emotive event in the past; this potent memory route for emotion induction may supersede other more deliberative (cognitive) mechanisms (Scherer \& Zentner, 2001). It is feasible to promote such extramusical associations through the creation of personal music videos: A music track that has been paired with a motivational and technically exemplary video may elicit a (learned) dispositional representation (Damasio, 1994) of a facilitative emotional state via Scherer and Zentner's memory route.

Once a music track has been selected, there is potential to modify some physical attributes of the listening situation at the delivery stage, to mediate the experienced emotional intensity. Precompetitive emotions may persist and fluctuate over the course of 1 week (Hanton et al., 2004); therefore, listening-performance onset delay was included in the model. According to Sloboda and Juslin (2001), the intrinsic music property tempo is one of the most potent determinants of emotional response. Contemporary technology affords the music consumer the opportunity to manipulate such modifiable music properties, and the mode of delivery (e.g., iPod via headphones) considerably affects the fidelity of the reproduction of the original sound (contextual features; Scherer \& Zentner, 2001). Also, the global proliferation of MP3 players means that music consumers are afforded a unique privatized auditory environment, regardless of location. This portability has important implications for an athlete's perception of, and affective response to, his or her 
environment — external (Baumgartner et al., 2006) or internal (Copeland \& Franks, 1991). Hence, modifiable music properties and mode of delivery were important additions to a contemporary model of music listening in sport.

Because modern MP3-playing technology features, such as "time scaling," enable the user to alter the tempo of a track without affecting its pitch, the same track can satisfy a greater number of preperformance needs. Athletes can moderate both the intensity and content of experienced precompetitive emotions by manipulating the intrinsic (e.g., tempo) and extrinsic (e.g., extramusical associations) properties of their music selections according to the demands of the sport or subcomponent of that sport. Researchers J.F. Thayer and Faith (2001) noted that "valence represents the evaluative outcome necessary to initiate an approach or withdrawal response, and arousal reflects the investment in the directional tendency" (p. 456). A loud, fast, and highly disliked track may be appraised as not only very unpleasant, but also as potentially harmful, resulting in (paradoxically) adaptive reorienting motor responses (see Zentner \& Kagan, 1996).

Players unanimously rated all selected tracks as highly liked $(M=10.1)$ and highly arousing $(M=9.3)$, regardless of intended emotional outcome, including tracks purportedly selected for relaxation. This finding is comparable to that of Saarikallio and Erkkilä (2007), whose participants used music predominantly to strengthen positive feelings, to move away from negative feelings, and to increase emotional intensity (R.E. Thayer, Newman, \& McClain, 1994). However, the present quantitative data may also reflect the nature of a sport that is intensely competitive and requires frequent and intense bursts of energy; relaxed in this context may refer to playing style, as opposed to complete psychophysical relaxation:

So, in my mind, I feel like I've got to be calm and relaxed, but I've still got to have energy, and, like run down balls and things like that. So it reflects how I want to be in a tennis match. (Participant 12)

The tempo of tracks associated with relaxation was also noticeably slower than for tracks selected for other emotional outcomes. Conversely, tracks associated with "psyched up" were played at a higher intensity $(M=102.3 \mathrm{dBA})$ and exhibited faster tempi $(M=120.9 \mathrm{bpm})$ than all other tracks, consistent with Scherer and Zentner's (2001) suggestion that proprioceptive feedback prompts the individual to couple internal rhythms with such external drivers. This is also supported by research into the relationship between exercise heart rate and preferred music tempo (Karageorghis, Jones, et al., 2006). However, these quantitative data contrast with the high subjective arousal values provided for all tracks used for relaxation. This appears to reinforce the notion that strong emotional experiences with music are influenced by situational, musical, and personal factors and may also reflect Saarikallio and Erkkilä's (2007) unification of relaxation and getting energy goals of music listening into an ultimate regulatory strategy of revival.

Visual imagery is an important strategy by which athletes can regulate their emotions (Jones, 2003), and it emerged as a theme in interview data. However, the present participants also reported auditory imagery (e.g., singing to oneself) as a consequence of music listening. Auditory imagery obeys the same neural principles as visual imagery: Association cortex reconstructs the original percept, such that it is possible to "have a song on the brain" in the absence of the physical stimulus, especially when the track is familiar (Kraemer, Macrae, Green, \& Kelley, 2005). 
Therefore, singing the lyrics of a familiar music track to oneself may be another powerful means for achieving a performance-facilitating emotional state; prior combination of the familiar track with an emotive video may enhance this effect further (Baumgartner et al., 2006).

At all stages of data collection, participants reported an attentional focus shift through music listening. Diary data (Table 3) suggests that this was primarily dissociative, in line with past research (Szabo et al., 1999); however, exercise intensity was not a limiting factor, as the majority of listening episodes occurred in a nonexercising state. Therefore, singing may not only enable athletes to dissociate from stressors in the competitive environment, but it could also function as part of a preperformance routine to promote automaticity; this active attentional manipulation would render overdeliberation difficult, thereby safeguarding against choking (Baumeister, 1984). Neurophysiology researchers are increasingly identifying the neural correlates of emotional responses to music (e.g., Menon \& Levitin, 2005), and wider availability of neural mapping technology means that we can now more readily investigate the relation between preperformance music and activation of brain areas involved in self-referential processes, for example. This could extend to investigation of these regions when attending to visual stimuli immediately after music listening.

Valence is a fundamental component of emotional life (e.g., Russell, 1980) and happiness - a component of the feeling of pleasure-is a key emotional construct in contemporary sport emotion research (Jones et al., 2005). The recurrence of pleasure and displeasure throughout all stages of data collection corroborated the presence of positive or negative valence in all recorded emotional responses. Diary responses indicated improved or maintained mood as a consequence of music listening, consistent with past research (R.E. Thayer, Newman, \& McClain, 1994). Pleasure was also very evident in participants' facial expressions, but these data were somewhat limited, which is unfortunate when considering the universality and predictive value of facial expressions of emotions (Russell \& Bullock, 1985). This was due largely to the absence of electromyographic (EMG) measures. Witvliet and Vrana (2007) found that participants' zygomatic (smiling) EMG activity was greater for high-arousal positive music than for all other music, and corrugator (frowning) activity was decreased with increased exposure to and/or familiarity with all music. Participants in the present study selected only highly familiar music; therefore, the emotions being expressed-facially or otherwise-were predisposed to be highly positive.

Another limitation of the present study was the fact that only 2 of the 14 participants had sufficient knowledge of musical structure to articulate some of the properties of the music they had selected. As a consequence, it was difficult to accurately discriminate the role of different intrinsic sources in determining participants' emotional responses to their music selections. The use of an instrument such as the BMRI-2 (Karageorghis, Priest et al., 2006) may circumvent this. Participants rated all music selections as highly liked and highly arousing. Therefore, correlating BMRI-2 item scores with Affect Grid (Russell et al., 1989) ratings, for example, may enable us to more accurately identify the relative contributions of extrinsic and intrinsic sources of emotion in athletes' responses to highly liked, highly arousing music. 


\section{Conclusion}

In summary, one of the most notable and recurrent themes throughout all stages of data collection was the active use of music as an emotional regulation strategy, corroborating past findings (Gluch, 1993). A host of environmental and contextual factors appear to influence an individual's music preferences, culminating in a highly individualized portfolio of music tracks. Although components within the first stage of the model will serve to sensitize the practitioner or athlete to the selection of appropriate music, there is low potential here for intervention. Conversely, the factors at the music selection and delivery stages are easily manipulable and represent a potentially fruitful avenue for future investigation. For example, increasing the tempo and/or intensity of a musical excerpt may increase the magnitude of an affective response and concomitant action tendencies (Frijda, 1986) such as increased motor behavior. This component of the fight-flight response not only relates to Damasio's (2000) life-preservation role for emotions, but it could also mean the difference between sporting success and failure.

\section{References}

Amezcua, C., Guevara, M.A., \& Ramos-Loyo, J. (2005). Effects of musical tempi on visual attention ERPs. International Journal of Neuroscience, 115, 193-206.

Atkinson, G., Wilson, D., \& Eubank, M. (2004). Effects of music on work-rate distribution during a cycling time trial. International Journal of Sports Medicine, 25, 611-615.

Baumeister, R.F. (1984). Choking under pressure: Self-consciousness and paradoxical effects of incentives on skillful performance. Journal of Personality and Social Psychology, 46, 610-620.

Baumgartner, T., Lutz, K., Schmidt, C.F., \& Jäncke, L. (2006). The emotional power of music: How music enhances the feeling of affective pictures. Brain Research, 1075, 151-164.

Boutcher, S.H., \& Trenske, M. (1990). The effects of sensory deprivation and music on perceived exertion and affect during exercise. Journal of Sport \& Exercise Psychology, 12, 167-176.

Copeland, B.L., \& Franks, B.D. (1991). Effects of types and intensities of background music on treadmill endurance. Journal of Sports Medicine and Physical Fitness, 31, 100-103.

Crust, L., \& Clough, P.J. (2006). The influence of rhythm and personality in the endurance response to motivational asynchonrous music. Journal of Sports Sciences, 24, 187-195.

Damasio, A. (1994). Descartes' error: Emotion, reason, and the human brain. London: Penguin.

Damasio, A. (2000). The feeling of what happens: Body, emotion and the making of consciousness. London: Vintage.

Dey, I. (2003). Grounded theory. In C. Seale, G. Gobo, J.F. Gubrium \& D. Silverman (Eds.), Qualitative research practice (pp. 80-93). Thousand Oaks, CA: Sage.

Edmonds, W.A., Mann, D.T.Y., Tenenbaum, G., \& Janelle, C.M. (2006). Analysis of affectrelated performance zones: An idiographic method using physiological and introspective data. Sport Psychologist, 20, 40-57.

Ekman, P. (1972). Universals and cultural differences in facial expressions of emotion. Paper presented at the Nebraska Symposium on Motivation, Lincoln, Nebraska. 
Ekman, P., Levenson, R.W., \& Friesen, W.V. (1983). Autonomic nervous system activity distinguishes among emotions. Science, 221, 1208-1210.

Frijda, N.H. (1986). The emotions. New York: Cambridge University Press.

Gabrielsson, A. (2001). Emotions in strong experiences with music. In P. Juslin \& J.A. Sloboda (Eds.), Music and emotion: Theory and research (pp. 431-449). Oxford, UK: Oxford University Press.

Glaser, B., \& Strauss, A. (1967). The discovery of grounded theory. Chicago: Aldine.

Gluch, P.D. (1993). The use of music in preparing for sport performance. Contemporary Thought, 2, 33-53.

Hanin, Y.L. (2000). Emotions in sport. Champaign, IL: Human Kinetics.

Hanton, S., Thomas, O., \& Maynard, I. (2004). Competitive anxiety responses in the week leading up to competition: The role of intensity, direction and frequency dimensions. Psychology of Sport and Exercise, 5, 169-181.

Jones, M.V. (2003). Controlling emotions in sport. Sport Psychologist, 17, 471-486.

Jones, M.V., Lane, A.M., Bray, S.R., Uphill, M., \& Catlin, J. (2005). Development and validation of the Sport Emotion Questionnaire. Journal of Sport \& Exercise Psychology, 27, 407.

Karageorghis, C.I., Drew, K.M., \& Terry, P.C. (1996). Effects of pretest stimulative and sedative music on grip strength. Perceptual and Motor Skills, 83, 1347-1352.

Karageorghis, C.I., Jones, L., \& Low, D.C. (2006). Relationship between exercise heart rate and music tempo preference. Research Quarterly for Exercise and Sport, 26, 240-250.

Karageorghis, C.I., Priest, D.L., Terry, P.C., Chatzisarantis, N.L.D., \& Lane, A.M. (2006). Redesign and initial validation of an instrument to assess the motivational qualities of music in exercise: The Brunel Music Rating Inventory-2. Journal of Sports Sciences, 24, 899-909.

Karageorghis, C.I., Terry, P.C., \& Lane, A.M. (1999). Development and initial validation of an instrument to assess the motivational qualities of music in exercise and sport: The Brunel Music Rating Inventory. Journal of Sports Sciences, 17, 713-724.

Kraemer, D.J.M., Macrae, C.N., Green, A.E., \& Kelley, W.M. (2005). Musical imagery: Sound of silence activates auditory cortex. Nature, 434, 158.

Larson, R. (1995). Secrets in the bedroom: Adolescents' private use of media. Journal of Youth and Adolescence, 24, 535-550.

Lazarus, R.S. (1991). Emotion and adaptation. New York: Oxford University Press.

Panksepp, J. (1998). Affective neuroscience: The foundations of human and animal emotions. New York: Oxford University Press.

Lincoln, Y.S., \& Guba, E.G. (1985). Naturalistic enquiry. Beverley Hills, CA: Sage.

Menon, V., \& Levitin, D.J. (2005). The rewards of music listening: Response and physiological connectivity of the mesolimbic system. NeuroImage, 28, 175-184.

Miles, M.B., \& Huberman, A.M. (1994). Qualitative data analysis: An expanded sourcebook (2nd ed.). Thousand Oaks, CA: Sage.

North, A.C., \& Hargreaves, D.J. (1995). Subjective complexity, familiarity, and liking for popular music. Psychomusicology, 14, 77-93.

North, A.C., \& Hargreaves, D.J. (1997). Liking, arousal potential, and the emotions expressed by music. Scandinavian Journal of Psychology, 38, 45-53.

Patton, M.Q. (2002). Qualitative research and evaluation methods (3rd ed.). Thousand Oaks, CA: Sage.

QSR. (2003). NVivo (Version 2.0) [Computer software]. Doncaster, Victoria, Australia: QSR International Pty Ltd.

Rapley, T. (2003). Interviews. In C. Seale, G. Gobo, J.F. Gubrium, \& D. Silverman (Eds.), Qualitative research practice (pp. 15-33). Thousand Oaks, CA: Sage. 
Ritossa, D.A., \& Rickard, N.S. (2004). The relative utility of 'pleasantness' and 'liking' dimensions in predicting the emotions expressed by music. Psychology of Music, 32, $5-22$.

Russell, J.A. (1980). A circumplex model of affect. Journal of Personality and Social Psychology, 39, 1161-1178.

Russell, J.A., \& Bullock, M. (1985). Multidimensional scaling of emotional facial expressions: Similarity from preschoolers to adults. Journal of Personality and Social Psychology, 48, 1290-1298.

Russell, J.A., Weiss, A., \& Mendelsohn, G.A. (1989). Affect Grid: A single-item scale of pleasure and arousal. Journal of Personality and Social Psychology, 57, 493-502.

Saarikallio, S., \& Erkkilä, J. (2007). The role of music in adolescents' mood regulation. Psychology of Music, 35, 88-109.

Scherer, K.S. (2004). Which emotions can be induced by music? What are the underlying mechanisms? And how can we measure them? Journal of New Music Research, 33, 239-251.

Scherer, K.R., \& Zentner, M.R. (2001). Emotional effects of music: Production rules. In P. Juslin \& J.A. Sloboda (Eds.), Music and emotion: theory and research (pp. 361-392). Oxford, UK: Oxford University Press.

Simpson, S.D., \& Karageorghis, C.I. (2006). The effects of synchronous music on 400-m sprint performance. Journal of Sports Sciences, 24, 1095-1102.

Sloboda, J.A., \& Juslin, P.N. (2001). Psychological perspectives on music and emotion. In P.N. Juslin \& J.A. Sloboda (Eds.), Music and emotion: Theory and research (pp. 71104). New York: Oxford University Press.

Strauss, A., \& Corbin, J. (1998). Basics of qualitative research: Techniques and procedures for developing grounded theory. London: Sage.

Szabo, A., Small, A., \& Leigh, M. (1999). The effects of slow- and fast-rhythm classical music on progressive cycling to physical exhaustion. Journal of Sports Medicine and Physical Fitness, 39, 220-225.

Thayer, J.F., \& Faith, M. (2001). A dynamical systems interpretation of a dimensional model of emotion. Scandinavian Journal of Psychology, 42, 121-133.

Thayer, R.E., Newman, J.R., \& McClain, T.M. (1994). Self-regulation of mood: Strategies for changing a bad mood, raising energy, and reducing tension. Journal of Personality and Social Psychology, 67, 910-925.

Witvliet, C.V.O., \& Vrana, S.R. (2007). Play it again Sam: Repeated exposure to emotionally evocative music polarises liking and smiling responses, and influences other affective reports, facial EMG, and heart rate. Cognition and Emotion, 21, 3-25.

Zentner, M.R., \& Kagan, J. (1996). Perception of music by infants. Nature, 383, 29.

Manuscript submitted: April 4, 2006

Revision accepted: May 15, 2007 